\title{
Word Pairs Learning
}

National Cancer Institute

\section{Source}

National Cancer Institute. Word Pairs Learning. NCI Thesaurus. Code C120331.

A component of the Children's Memory Scale. A child is read a list of paired words and then asked to say the second word after being told the first. The list is presented three times in this fashion. 